\title{
The Roles of Self-Regulation and Self-Control in Procrastination
}

\author{
Faramarz Ramzi and Omid Saed* \\ Department of Clinical Psychology, Zanjan University of Medical Sciences, Iran
}

Submission: August 11, 2019; Published: September 17, 2019

*Corresponding author: Omid Saed, Department of Clinical Psychology, School of Medicine, Zanjan University of Medical Sciences, Zanjan, Iran

\begin{abstract}
Procrastination is a prevailing and pernicious form of self-regulatory failure. This common phenomenon can occur across a variety of life domains. Procrastination and impaired self-control or self-regulation often occur for many individuals which can lead to difficulty with daily issues such as controlling impulses and maintaining attention. Understanding how mechanisms of self-control and self-regulation work is an important issue. Despite large body research, findings in this field are often uncertain and its mechanisms and causes are ambiguous. The goal of this mini review is to explore the roles of self-control and self-regulation in procrastination.
\end{abstract}

Keywords: Procrastination; Self-regulation; Self-control; Mechanisms; Short-term emotion regulation

\section{Introduction}

Many people have reported procrastination at least once. However, a significant population admitted that procrastination has become a habit for them. Tuckman (1991) has defined procrastination as the tendency to delay doing or starting tasks because of absence or lack of self-regulation [1]. In another definition, Steel (2007) has defined procrastination as voluntary delaying actions despite predicting worsening events [2]. In other words, the general tendency to delay tasks until another time is called procrastination [3].

Procrastination is not a new phenomenon. In fact, its scientific history goes back to 20-30 years ago. It seems that procrastination aims to improve one's life, but almost always leads to stress, disorganization, and failure [4].

Most studies of procrastination have focused more on its downside. For example, Ferrari and Tice regarded procrastination as a form of self-handicapping or maintaining threatened selfesteem [5]. Conversely, some researchers consider the positive side of procrastination. The result of their research shows that delaying some tasks is logical and makes people feel good [6]. Some researchers have identified procrastination as short-term emotion regulation [5]. Some researchers believe that procrastination is a habit [7] or a personality trait [8]. In some cases, researchers believe that procrastination may have benefits. For example, Cho and Choi reported that some students enjoy working under time-pressure and deliberately choose to procrastinate [9]. Tice and Baumeister concluded that procrastination in the short term produces pleasure and enjoyment, but in the long term, it brings stress and illness [5].

Research into the cause of procrastination has received much attention from researchers, leading to the development of several models to understand the nature of procrastination [10]. These models have helped researchers identify the cause of procrastination and address various aspects of it [11]. Researchers with a behavioral perspective on procrastination focus on the amount of behavior and the frequency of task delay [12]. Most researchers believe that self-regulation is one of the strongest behavioral predictors of procrastination. In this view, self-regulation and self-control tendencies are important variables for evaluating behavioral procrastination [13]. The purpose of this article is to investigate the relationship between self-control and self-regulation in procrastination and the effect of these factors on the daily performance of individuals.

\section{Self-regulation and procrastination}

One of the factors that negatively affect people's daily lives is a self-regulatory failure. Some researchers emphasize that procrastination is strongly associated with self-regulation failure. Self-regulation refers to self-regulated thoughts, feelings, and behaviors that guide individuals to set personal goals [14]. In another definition, Heatherton and Baumeister defined self-regulation failure as under regulation or mis regulation 
of individuals in an attempt to initiate, change, or override a behavior [15].

Havel and Watson believe that disorganization and low achievement motivation are the characteristics of self-regulation failure in procrastination [16]. Sirois and Picryl have shown that short-term mood repair is seen as a self-regulation failure that is rooted in an unpleasant emotional state [17]. Tice et al. [5] noted that people procrastinate when they are working on a task that causes unpleasant emotions and when one believes that this mood changes with the pursuit of pleasurable alternative activities. In one study, Senecal et al. [18] found that self-regulation alone explains $25 \%$ of the variance in academic procrastination. Recent evidence has shown that self-regulation plays a very important role in students' psychological well-being [18]. Hofer et al. [19] showed that students with high levels of self-regulation ability reported higher levels of well-being [19].

\section{Self-control and procrastination}

Another important factor associated with procrastination is self-control. Gottfredson and Hirschi defined self-control as the capacity and ability of individuals to control emotion, behavior, and cognition [20]. Studies have shown that selfcontrol is a good predictor of procrastination [21]. People who procrastinate actually cannot control their behavior and prefer pursuing pleasurable short-term activities to their important goals [21]. High self-control is associated with a variety of positive outcomes, such as increased educational outcomes, low probability of crime and delinquency, and positive social impact. Low self-control is associated with poor educational outcomes, increased aggression, and substance abuse. These results are because people with low self-control are very impulsive, responding promptly to their environmental stimuli, and are seeking immediate pleasure. In addition, they lack perseverance in their work [20]. Studies on procrastination have shown that low self-control causes procrastination. Students with high self-control are aware of their learning process and are more successful in balancing and speeding up their tasks. On the other hand, students with low self-control have difficulty with this learning process, which results in procrastination and lack of academic progress. Ultimately, self-control is a predictor of better academic achievement [22].

\section{Mechanisms of self-regulation and self-control on procrastination}

Explanations of the procrastination mechanism by temporal discounting [23], task-aversiveness [24], fear of failure [25], Selfhandicapping [8], or traits procrastination [25] have concluded that the cause of procrastination is a lack of self-control [26].

Emotion and motivation play a central role in self-control and procrastination. Emotions help us pay close attention to specific stimuli. Emotions can be related to rewarding or punishing stimuli. Motivation makes the goals desirable, while the emotional state appears when the individual has reached their goal.

In self-regulation, individuals try to regulate processes by modifying their responses [5]. In fact, a kind of self-regulation is emotional regulation. Short-term mood repair is a kind of emotional regulation that focuses on short-term mood and affects regulation. In fact, procrastination occurs when one delays the pursuit of long-term goals for short-term mood repair. Negative moods provide the context for self-regulation failure. Also, exerting self-control leads to negative moods. Tice and Broslowski examined the relationship between self-regulation failure in procrastination and the essential role that emotion regulation plays in self-control. These researchers believe that focusing on mood and affect regulation in the short term will lead to the failure of self-control in other areas of life. In procrastination, aversive tasks cause anxiety and worry, and avoiding the task is a strategy to get rid of this negative mood. When we put too much emphasis on feeling, in fact, we fail to override impulses to avoid the task [5].

Procrastination can also be the result of the exhaustion of self-control mechanisms in the face of goals. Volitional acts such as controlling impulses, overriding habitual responses, and decision-making depend on self-control [27]. In fact, resource depletion hinders self-control [28]. According to the strength model of self-control, self-control has limited resources to control responses [29]. When self-control is low and there is no time for rest and replenish, it results in ego-depletion in subsequent tasks [30]. Procrastination occurs more often when it requires for a high level of self-control. In fact, procrastination is a direct result of ego-depletion [31].

\section{Conclusion}

This study aimed to introduce self-control and self-regulation as factors underlying many of behaviors, especially in the field of procrastination. Many studies are showing that self-control and self-regulation play an important role in explaining the nature of procrastination. People with low self-control and self-regulation are susceptible to distraction and pleasurable environmental stimuli, given this, it can be said that people with low selfcontrol and self-regulation, although aware of its undesirable consequences, are likely to delay their tasks deliberately for short-term and desirable rewards. The reason for this could be that when people are faced with difficult and aversive tasks, their desire to find alternative activities immediately increases. Also, recent findings have shown that people with low selfcontrol and self-regulation procrastinate because they have difficulty regulating goals and quitting enjoyable activities. Given that low self-regulation and self-control lead to severe health consequences, little attention has been paid to this area of study. It is necessary that interventions and treatments which aim to improve the situation in procrastination, consider self-control and self-regulation components in their treatment. Targeting the 


\section{Psychology and Behavioral Science International Journal}

lack of self-control and self-regulation strategies can be the core of procrastination treatment protocols.

\section{Acknowledgment}

This study has been approved by the Ethics Committee of Zanjan University of Medical Sciences (Ethics committee reference number: ZUMS.REC.1397.278). This research was officially registered as Residency thesis (code: A-12-924-10) at the School of Medicine, Zanjan University of Medical Sciences.

\section{References}

1. Tuckman BW (1991) The development and concurrent validity of the procrastination scale. Educational and psychological measurement 51(2): 473-480

2. Steel P (2007) The nature of procrastination: A meta-analytic and theoretical review of quintessential self-regulatory failure. Psychol Bull 133(1): 65-94.

3. Lay CH (1986) At last, my research article on procrastination. J of research in personality 20(4): 474-495.

4. Özer BU, Saçkes M (2011) International Conference on Education and Educational Psychology (ICEEPSY 2010) Effects of Academic Procrastination on College Students' Life Satisfaction. Procedia-Social and Behavioral Sciences 12: 512-519.

5. Tice DM, Bratslavsky E (2000) Giving in to feel good: The place of emotion regulation in the context of general self-control. Psychological inquiry 11(3): 149-159.

6. Choi JN, Moran SV (2009) Why not procrastinate? Development and validation of a new active procrastination scale. J Soc Psychol 149(2): 195-212.

7. Ellis A (1997) Using Rational Emotive Behavior Therapy techniques to cope with disability. Professional Psychology: Research and Practice 28(1): 17-22.

8. Ferrari JR (1991) Compulsive procrastination: Some self-reported characteristics. Psychol Rep 68(2): 455-458.

9. Chu AH, Choi JN (2005) Rethinking procrastination: Positive effects of" active" procrastination behavior on attitudes and performance. J Soc Psychol 145(3): 245-264.

10. Dietz F, Hofer M, Fries S (2007) Individual values, learning routines and academic procrastination. Br J Educ Psychol 77(4): 893-906.

11. Kachgal MM, Hansen LS, Nutter KJ (2001) Academic procrastination prevention/intervention: Strategies and recommendations. J of Developmental Education 25(1): 14.

12. Beck BL, Koons SR, Milgrim DL (2000) Correlates and consequences of behavioral procrastination: The effects of academic procrastination, self-consciousness, self-esteem and self-handicapping. J of social behavior and personality 15(5): 3 .

13. Ariely D, Wertenbroch K (2002) Procrastination, deadlines, and performance: Self-control by precommitment. Psychological science 13(3): 219-224.
14.Zimmerman BJ (2000) Attaining self-regulation: A social cognitive perspective. Handbook of self-regulation p. 13-39.

15. Baumeister RF, Heatherton TF (1996) Self-regulation failure: An overview. Psychological inquiry 7(1): 1-15.

16. Howell AJ, Watson DC (2007) Procrastination: Associations with achievement goal orientation and learning strategies. Personality and Individual Differences 43(1): 167-178.

17. Sirois F, Pychyl T (2013) Procrastination and the priority of short-term mood regulation: Consequences for future self. Social and personality psychology compass 7(2): 115-127.

18. Senecal C, Koestner R, Vallerand RJ (1995) Self-regulation and academic procrastination. The journal of social psychology 135(5): 607-619.

19. Hofer J, Busch H, Kärtner J (2011) Self-regulation and well-being: The influence of identity and motives. E J of Personality 25(3): 211-224.

20. Gottfredson MR, Hirschi T (1990) A general theory of crime. Stanford University Press.

21. Ferrari JR, Johnson JL, McCown WG (1995) Procrastination and task avoidance: Theory, research, and treatment. Springer Science \& Business Media.

22. Duckworth AL, Taxer JL, Eskreis-Winkler L, Galla BM, Gross JJ (2019) Self-Control and Academic Achievement. Annual Review of Psychology 70: 373-399.

23. Monterosso J, Ainslie G (2007) The behavioral economics of will in recovery from addiction. Drug Alcohol Depend 90(1): S100-S111.

24. Blunt AK, Pychyl TA (2000) Task aversiveness and procrastination: A multi-dimensional approach to task aversiveness across stages of personal projects. Personality and Individual Differences 28(1): 153167.

25. Schouwenburg HC, Lay C, Pychyl T, Ferrari J (2006) Counseling the procrastinator in academic settings: American Psychological Association.

26. Wohl MJ, Pychyl TA, Bennett SH (2010) I forgive myself, now I can study: How self-forgiveness for procrastinating can reduce future procrastination. Personality and Individual Differences 48(7): 803808.

27. Hagger MS, Wood C, Stiff C, Chatzisarantis NL (2010) Ego depletion and the strength model of self-control: a meta-analysis. Psychol Bull 136(4): 495-525.

28. Bauer IM, Baumeister RF (2011) Self-regulatory strength. Handbook of self-regulation: Research, theory, and applications 2: 64-82.

29. Carter EC, McCullough ME (2014) Publication bias and the limited strength model of self-control: has the evidence for ego depletion been overestimated?. Front Psychol 5: 823.

30. Baumeister RF, Vohs KD, Tice DM (2007) The strength model of selfcontrol. Current directions in psychological science 16(6): 351-355.

31. Schraw G, Wadkins T, Olafson L (2007) Doing the things we do: A grounded theory of academic procrastination. J of Educational psychology 99(1): 12-25. 
This work is licensed under Creative Commons Attribution 4.0 License

DOI: 10.19080/PBSIJ.2019.13.555863
Your next submission with Juniper Publishers will reach you the below assets

- Quality Editorial service

- Swift Peer Review

- Reprints availability

- E-prints Service

- Manuscript Podcast for convenient understanding

- Global attainment for your research

- Manuscript accessibility in different formats

( Pdf, E-pub, Full Text, Audio)

- Unceasing customer service

Track the below URL for one-step submission https://juniperpublishers.com/online-submission.php 